\title{
A Firm-Level Innovation Management Framework and Assessment Tool for Increasing Competitiveness
}

Sorin Cohn

\author{
"I often say that when you can measure what you are" \\ speaking about, and express it in numbers, you know \\ something about it; but when you cannot express it in \\ numbers, your knowledge is of a meagre and \\ unsatisfactory kind; it may be the beginning of knowledge, \\ but you have scarcely, in your thoughts, advanced to the \\ stage of science, whatever the matter may be.
}

Lord Kelvin (1824-1907)

Mathematical physicist and engineer

\begin{abstract}
Innovation depends on much more than just technology and $R \& D$. It is a means to an end - competitive success and higher market value - and it needs to be managed strategically and methodically for tangible corporate performance where it matters: in the market. This article introduces a comprehensive corporate innovation management framework (v-CIM) and a targeted competitiveness assessment tool (i-TCA). Properly used by corporate leaders, this framework and its associated tool enable innovation managers to decide on priorities for competitive development, adopt appropriate innovation strategies to meet corporate goals, monitor progress, make adjustments, and help create and maintain a culture of innovation that is aligned with business goals.
\end{abstract}

\section{Introduction}

Firms innovate to create value and maintain or enhance their competitive position in the market. Their attitude towards innovation, the types of innovation they pursue, and the levels of risk they accept depend on the situation of the firm in its market. Firm-level innovation is not a goal in itself, but the means to achieving corporate success and higher market value, which are predicated on:

\section{A market of sufficient size or growth.}

2. The competitiveness of the firm in serving its market, as determined by: i) the desirability and affordability of the firm's products and services; ii) the effectiveness of the firm's interactions with the market in terms of understanding it, promoting to it, collaborating with suppliers and partners, accessing its targeted customers, and satisfying its customers and the other stakeholders; iii) the efficiency of the firm's operations (e.g., management, development, production, human resources, quality, distribution, supply, marketing); and iv) the firm's financial strength.

3. The culture of the organization, including leadership, skills competencies, etc.

4. Luck and timing, which are imponderable ingredients recognized by business leaders and military strategists from time immemorial.

Comprehensively, innovation is the process by which a firm creates value and differentiation through new or improved products or services, or new ways of pursuing the business goals and its operations - both within the organization and throughout its entire business environment. For a long time, managing innovation has been an art that is now becoming more of a science based on objective data and proven methodologies. 


\section{A Firm-Level Innovation Management Framework and Assessment Tool} Sorin Cohn

The broad spectrum of a firm's innovation goals and the interdependencies between various domains of innovation present numerous challenges to attempts at managing firm-level innovation effectively and efficiently. First, it is necessary for the firm to decide to compete through innovation and determine where to innovate. Then, it needs to select what to innovate, allocate the resources, organize each of the innovation activities as a project, and plan how to pursue them. The firm management must also determine how to evaluate its innovation activities and the overall innovation performance: what to measure and how to measure it. Once the innovation efforts are underway and results are being evaluated, the firm should decide on necessary adjustments (including project termination or change of direction), as well as who to reward and how. Because competition is perennial, firm-level innovation management is a continuous process, and the firm needs to extract as much learning from the present before proceeding anew to decide on where, when, and how to innovate next.

Innovation may be driven top-down by defining innovation strategies to be followed, planning the respective innovation projects, resourcing them, executing and evaluating them, and finally ensuring their implementation and commercialization. Innovation may also flow bottom-up, in which case it should be adopted, nurtured, managed, and rewarded to encourage more innovations to bloom.

Some of the main difficulties in managing firm-level innovation are due to inconsistent understanding (and models) of innovation and the lack of adequate measurement-based management methodologies and tools. Innovation is complex and multidimensional, and many firms have let important innovations languish or were incapable of maintaining their competitive position through continued innovation (Christensen, 1997; tinyurl.com/7onvohk).

Traditionally, innovation research focused on three dimensions: the source of the innovation (internal or external), the type of innovation (product, service, or process innovation), and the rationale for the innovation (voluntary initiative or a necessity demanded by competitive pressures in the market). Inadequate attention has been given to the interaction between innovation and the firm's organization and to the multitude of factors affecting innovation, some of which may be external to the firm itself (Tidd, 2001; tinyurl.com/pdtcuov).

An effective pursuit of market competitiveness through innovation requires a corporate leadership that is open to critical assessments of the company's position in the market and an organization prepared to strategically address necessary innovation pursuits based on realistic measurements of progress. Firm-level innovation management for competitive growth involves a multistage process that addresses:

1. Strategic competitiveness assessment and planning, including the determination of competitive imperatives, innovation strategies, specific innovation goals, and expected targets.

2. Establishing and maintaining a culture of innovation that permeates all corporate levels, is aligned with corporate goals and human-resources performanceevaluation systems, and operates symbiotically with risk management.

3. Adopting and using an effective firm-level innovation-management process based on a well-chosen model of innovation and effective management tools and metrics.

4. Pursuing continuous learning and adjustment that addresses both innovation activities and the choice of tools and metrics for fast adaptation to the changing needs of the company.

Systematically driving a company in its competitive progress requires an innovation-management framework that looks comprehensively at the complex multidimensional reality of the various domains of innovation within the firm. These management needs have been the impetus for the development - over the past 15 years of the author's business-development work with large and small firms in Canada, the United States, and Europe - of a firm-level innovation-management framework and an associated tool for the assessment of a company's competitive position in its targeted markets.

This article introduces the Value-Added Corporate Innovation Management (v-CIM) framework enabling a firm's leadership to undertake innovation activities strategically in a balanced approach across all the critical domains of competitiveness. Next, the paper outlines the importance of matching corporate vision and goals with a workable understanding of the competitive reality. On that basis, the paper presents the Intelligent Targeted Competitiveness Assessment (i-TCA) tool developed by the author. Several examples of real company assessments are described to illustrate the application and usefulness of the i-TCA tool. 


\section{A Firm-Level Innovation Management Framework and Assessment Tool} Sorin Cohn

\section{Innovation Management Models}

Various models of the innovation process have been offered in the literature to help firms manage their innovation activities with proper measurement techniques and tools. Initially, the focus was on the individual innovation process, as seen in the Linear Model (Davila et al., 2005; tinyurl.com/k86rs47), the Innovation Team Model (Källman, 2009; tinyurl.com/m23elnf), and the Innovation Value Chain (Hansen and Birkinshaw, 2007; tinyurl.com/m2bd8ko). These models have the merit of facilitating the management of individual innovation projects, but they do not enable an overall strategic look at innovation throughout the firm.

The contribution from external actors to the ideation, implementation, and commercialization of innovation has taken a greater significance in the context of the World Wide Web and globalization. The concept of "open innovation" (Chesbrough, 2003; tinyurl.com/kp33d22) is preoccupying strategists attempting to deliver the best ways to take advantage of, and defend against, the threats brought by the "democratization of innovation" (von Hippel, 2006; tinyurl.com/aygvzd2).

Firm-level innovation management requires models that enable prioritization of innovation activities and resource allocation in the context of present and future competitive needs.

The Business Growth Model was developed by Arthur D. Little to position innovations in a strategic context (Collins and Smith, 1999; tinyurl.com/m4p6jh7). It addresses innovation holistically by considering strategic issues on a par with the other domains of innovation as four interdependent elements. The model enables answers to and measurements of - the fundamental issues of innovation in a firm:

- Are the right things being addressed? (Stakeholder Strategies)

- Are these things done right? (Processes)

- Are there the necessary means and capabilities? (Resources)

- Does the firm get the best from its resources? (Organization and Culture)

The associated metrics require a time perspective for balancing past achievements with predictive measure- ments of potential innovation outcomes through corporate capabilities.

The Idea Funnel Model (Goffin and Mitchell, 2005; tinyurl.com/nydxx3s) pays more attention to the importance of innovation strategies in determining the selection, direction and execution of innovations, but it still does not consider all corporate capabilities or the importance of innovation in strategy itself.

The Structural Perspective Model (Muller et al., 2005; tinyurl.com/mzcub7x), further developed by InnovationPoint (Kaplan and Winby, 2007; tinyurl.com/p49twxy), looks at innovation from a capability, resource, and leadership view in an attempt at balancing all critical factors in the selection and management of innovations from inception to market valuation.

The more mathematically formal Axiomatic Design Model of the "innovation continuum" (Suh, 2010; tinyurl.com/ov9dfgo) was developed as a fully engineered process that starts from functional requirements and delivers design parameters. This model is focused on new products and services in a continuum of 12 essential steps necessary to take the idea to its completion as product in the market. The model has met with some success in helping South Korea develop its capabilities in the industrial sectors it considered essential for competitive domination.

Another model of merit is the INNOVAT10N Model (tinyurl.com/ke7m9n5), which was developed by Doblin in 1998 and was updated in 2011. This model focuses on 10 types of innovations that, if properly intertwined and managed, enable companies to develop competitive offerings aimed at generating higher returns thanks to insidious values that are more difficult to be copied entirely. The problem with this model is that it does not address certain areas of innovation explicitly - especially those related to corporate capabilities starting with culture, the organization, the variety of resources, and the processes that keep the corporation in action.

"Culture is key" was the conclusion of the recent studies by Booz \& Co on innovation and competitiveness in industry (Jaruzelski et al., 2011; tinyurl.com/lrtvbnm), with the corollary that a culture of innovation and the alignment of business goals with the right innovation strategies are more determinant factors than the amount of investments in research and development programs. 


\section{A Firm-Level Innovation Management Framework and Assessment Tool} Sorin Cohn

The 3M Company (2011; tinyurl.com/ppcd3ly) has developed its own model for managing innovation as a matrix interlacing the "outcomes" (i.e., products and services, marketing and customers, territories, technologies, etc.) with the key organizational structures $(R \& D$, marketing, national sales, operations, human resources, culture, etc.) in an effort to ensure that it is "planned, purposeful, and global".

\section{Value-Added Corporate Innovation Management Framework}

Managing a company requires a framework that looks comprehensively at the multidimensional intertwined reality of the various domains of innovation within the firm, thus allowing the firm's leadership to manage innovation strategically in a balanced approach across all the critical domains of competitiveness. The Value-Added Corporate Innovation Management (v-CIM) framework has been developed to address this need. As shown in Figure 1, the framework is represented as a pyramid composed of five layers, or domains:

1. Business Base: This is the foundation domain. It covers the firm's overall market understanding (including customers and competitors), its corporate business goals, its strategic imperatives, the dynamics of its business models, and its innovation strategies.
2. Resources: This domain covers the people within the company, the corporate facilities, infrastructure and tools, the technology platforms on which products and services are built, and the business partnerships and networks for external collaboration for taking full advantage of open-innovation opportunities (tinyurl.com/2ow32e).

3. Will and Culture: This domain addresses the leadership of the company, its governance, its organization, and its culture. As such, this domain represents the heart of the innovation complex, for without will, leadership, an appropriate structure, and a dynamic culture, not much new value will be created.

4. Solutions: This domain captures the "creations" of the company: the processes it uses and the products and services it sells. The managing of innovation is in itself one of the critical corporate processes because it encompasses most aspects of the firm, it is critical to the competitive evolution of the firm, and it requires special management attention.

5. Value: This domain sits at the pinnacle of the pyramid. It consists of the portfolio of corporate innovation outcomes: its financial outcomes, its customer base, its brand, its territorial position in the market, its social achievements, and its environmental impacts.

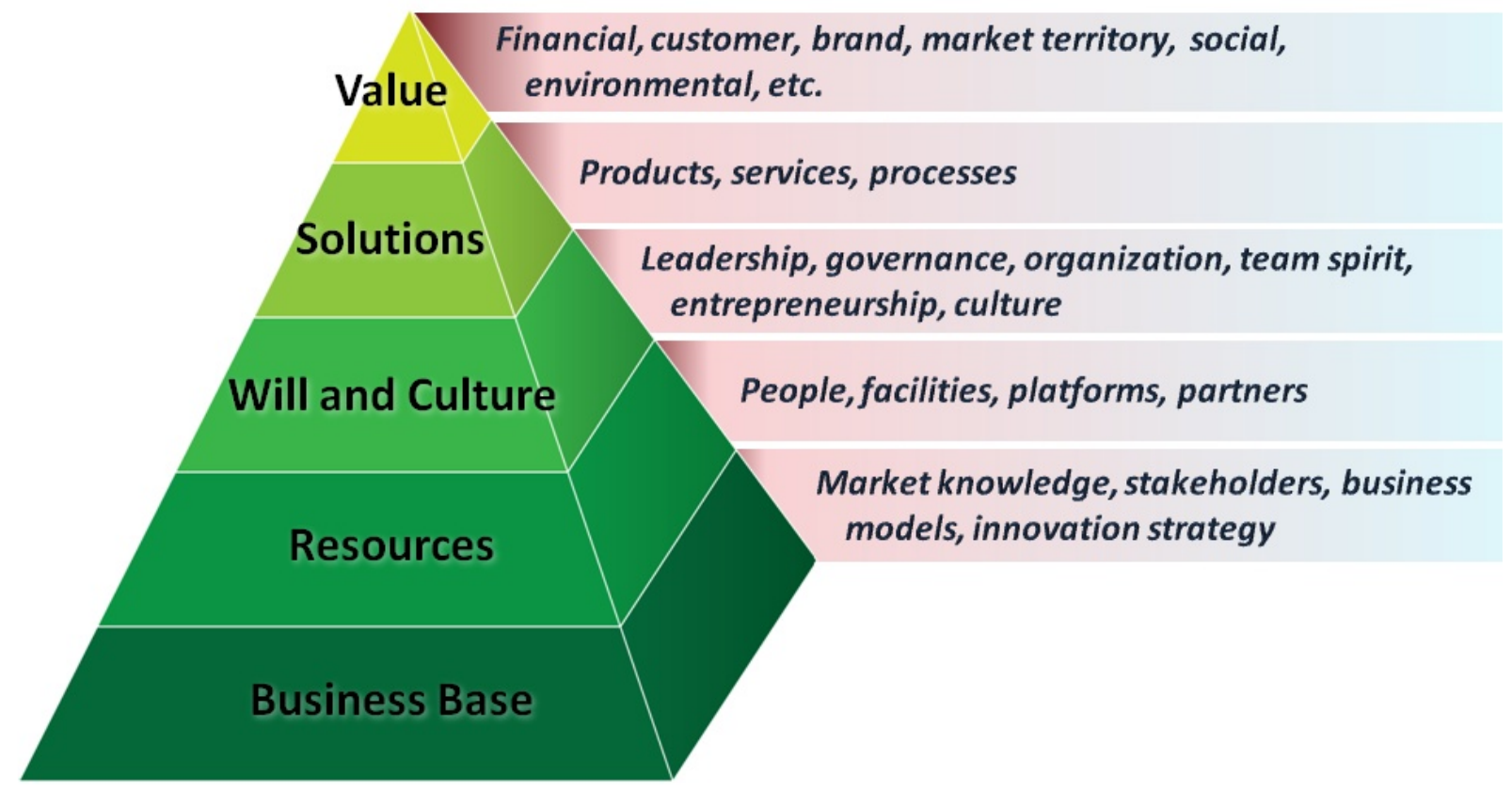

Figure 1. The five domains of the v-CIM framework 


\section{A Firm-Level Innovation Management Framework and Assessment Tool Sorin Cohn}

The v-CIM framework allows full correlation of innovation management with the firm's strategies. It enables an analysis of past performance as well as preparations (capabilities) for future achievements. The v-CIM framework has the benefit of directly capturing a multiplicity of time perspectives - historical, present and forward looking - by enabling the viewing and measurement of the real-time management of innovation processes together with the capabilities for further innovation.

In practice, the use of the v-CIM framework and its associated innovation metrics needs to be done according to the particular corporate perspective, such as a specific functional division/department within a corporation, a single product/service business firm, a multi-product/ service business company. These entities can apply the $\mathrm{v}$-CIM framework to each of their product lines and to the company overall, a more complex multi-business unit corporation within same sector, and the very complex multi-sector conglomerate, which requires a waterfall analysis of each of the conglomerate companies.

In all cases, the v-CIM framework enables the targeted selection of a balanced portfolio of indicators and associated metrics for effective measurement-based management of innovation in the company.

\section{Vision and Reality: Intelligent Targeted Competitiveness Assessment}

Competitive innovation management reflects an unrelenting drive towards achieving a firm's business goals. A company's management goals may be classified into three acceptable categories:

1. Managed-to-Sell (MtS): in general, this is a company building valuable intellectual property (IP) that leads to its acquisition by another company for the sake of access to the IP (and people), or simply to deny their own competitors access to that IP.

2. Managed-to-Endure (MtE): a company providing perennial (long term) financial rewards to its founders and investors.

3. Managed-to-Lead (MtL): a company managed to capture dominant revenue share in its addressed market segment and to provide outstanding perennial financial rewards to its founders and investors over a very long term.

Enhancing a company's position in its target markets is done through innovation directed at the areas of weak- ness vis-à-vis key competitors while taking advantage of competitive strengths. A realistic understanding of the business circumstances in which a company operates must be detailed enough to enable its leadership to make the necessary decisions and to pursue operative actions at any moment, as imposed by market dynamics and competitive threats or opportunities.

The objective for the author's development of the Intelligent Targeted Competitiveness Assessment (i-TCA) tool was to create a framework and the means for undertaking consistent and comparative analyses of a company's status and its evolutionary progress relative to primary competitors in its targeted markets. It was meant to be a monitoring tool, enabling corporate leaders to capture how the company perceives itself and to assess how well it is progressing on its plan for becoming more competitive. The i-TCA is also a retrospective tool, acting as a mirror that tells the company where it is weak and where it is strong. As well, it is a prospective tool, telling the company where it needs to innovate to achieve its goals. Finally, it is a team-building tool enabling and empowering the corporate management to active participation in strategic planning and innovation management.

The i-TCA software tool was designed in accordance with the v-CIM framework using FluidWare (fluid ware.com) online survey technologies. A CEO can achieve a quick, personal subjective assessment of the competitive situation in less than 20 minutes because most of the questions are framed with multiple-choice responses. More value can be achieved by using this software tool with the entire executive team because it uncovers divergences of opinions, enables the resolution of such divergences, and leads to a balanced, collective view of the situation and to a plan to address it.

The basic i-TCA tool consists of five sections, defined as sets of survey questions:

1. Company Background: elicits information about the company's business goals and its industry sector, size, age, location, and financial performance

2. Market Background: collects information on the size, locations, and competitive situations of primary and secondary targeted markets, as well as the origin of the primary competitors within them

3. Competitive Attributes: captures the key competitive attributes that define the culture of the company 


\section{A Firm-Level Innovation Management Framework and Assessment Tool}

\section{Sorin Cohn}

4. Collaboration: collects information on the company's use of external partners in a variety of domains

5. Competitive Assessment: contrasts the company's position against its targeted competitor across five domains that consist of 30 areas of competitive differentiation (listed below)

The competitiveness assessment can be done against the primary or secondary competitor in the primary market. Of course, the analysis could also target primary and secondary competitors in the secondary target market, and so on, thus enabling the management to take appropriately targeted decisions against its competitors.

In all cases, the i-TCA tool provides an at-a-glance competitiveness-assessment dashboard that is built as a radial map, which allows direct visual analytics. Each radius on the circular map in Figure 2 represents an area of competitive assessment, with zero competitive performance at the centre and $100 \%$ competitive leadership (domination) on the outside circle.
The areas of competitive assessment are grouped into five categories, which, in the basic i-TCA version contain the following parameters:

1. Business Position: business partners, brand, revenues, financial strength, channel quality, channel coverage, and government commercialization support

2. Market Knowledge: perception by market, frequency of marketing, quality of marketing, competitor knowledge, and market understanding

3. Corporate Culture: leadership, governance board, corporate processes, management of human resources, innovation management, and culture of innovation

4. Technology and Production: technology advancement, IP protection, speed of development, development affordability, production, and government technology support

5. Products and Services: suppliers, customer service, ease of use, performance, functionality, and affordability

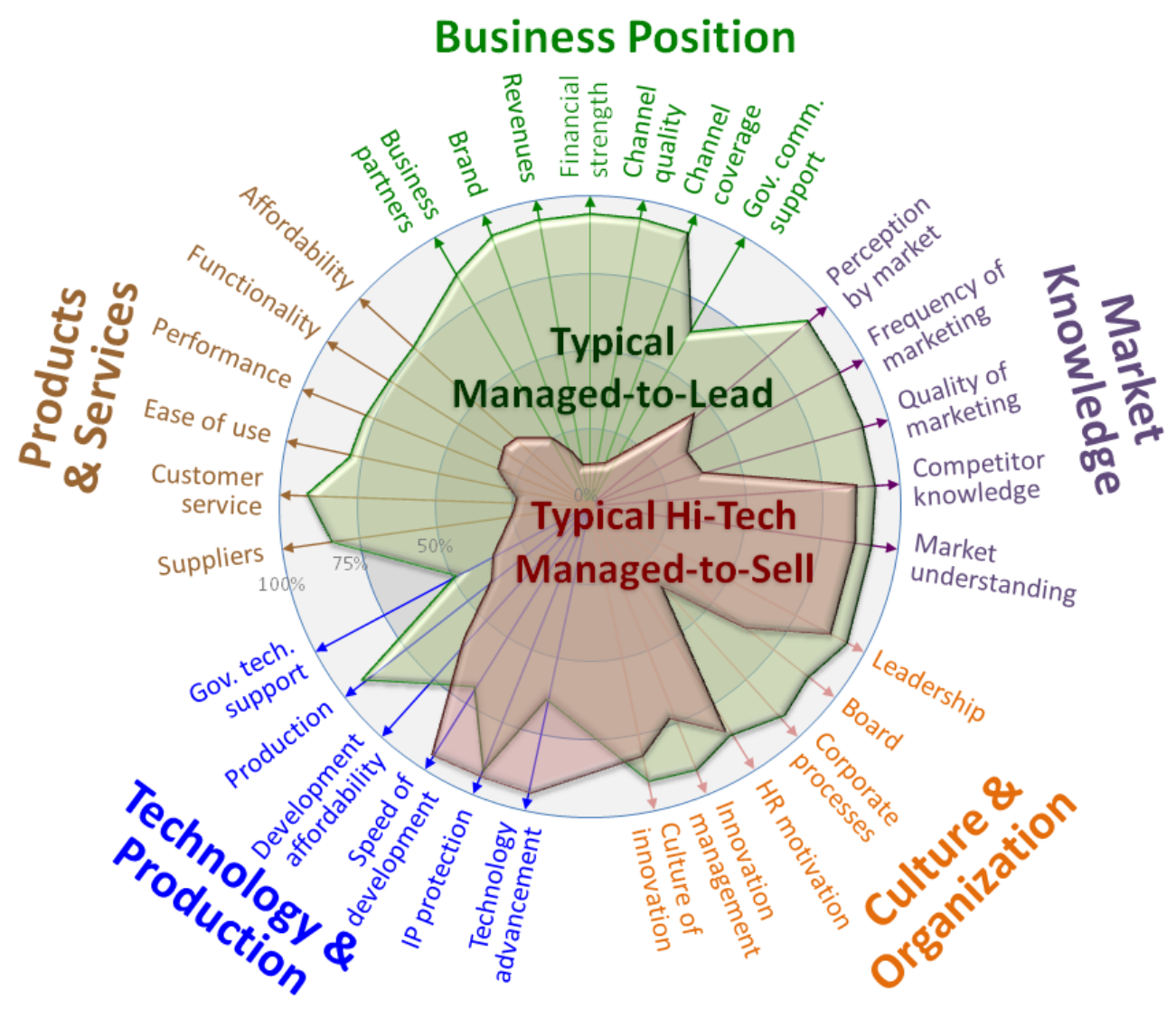

Figure 2. The competitiveness assessment dashboard 


\section{A Firm-Level Innovation Management Framework and Assessment Tool} Sorin Cohn

To guide the user, the background of the competitiveness-assessment dashboard also contains representative maps of typical MtS and MtL companies. Rarely is a company leading in all areas, but a typical MtL company (green) is close to the $100 \%$ performance circle in most areas. Leading competitors do not always have the best technologies or products, but they do offer the most appreciated solutions to their customers. In general, sustainably leading companies focus on their customers, while ensuring they have solid engineering, efficient operations, highly effective sales and marketing, and a strong culture of innovation. In contrast, a typical hi-tech MtS company (red) does not need to exhaust itself in areas that are not essential to its business goal - a quick and profitable sale of the company itself. For technology companies, this goal requires focus on technology excellence and the appropriate marketing of the company to potential acquirers while keeping an eye on threatening competitors. MtE companies usually fall in between MtL and MtS companies.

Beyond the individual use of the i-TCA tool by a company CEO, the methodology for use of the tool by a corporate team has four distinct phases:

1. Team Assessment Setup: This phase is initiated by a company's leader (the "client") decision to proceed with an intelligent competitive-assessment exercise. Clear objectives are established and the prime responsibilities for the assessment are determined. Next, initial instruction is given to the team, either by webinar or, preferably, in a face-to-face session. A full audio-visual presentation is available for dissemination from the author and its partners, but experience shows that live presentations and subsequent team discussions lead to better results by dispelling some participants' concerns. Also, there is better engagement following such live-team sessions. Once the decision is made, this phase may be as short as a few hours, with the timing largely dependent on the leadership ability to engage the necessary participants in the assessment.

2. Data Collection: In this phase, the online survey is made available to each team member. Data collection can be achieved in a day or two if all participants immediately respond online. In practice, it has been found useful to allow for one week and repeatedly call for the completion of the survey.

3. Analysis and Delivery: The data is processed using state-of-the-art survey tools and the author's analysis techniques. A report is made available, which in- cludes the competitiveness assessment dashboard and the first-level analysis of the variance between the perspectives of team members. This phase ends with a presentation to the client, with a focus on areas requiring further development.

4. Follow-up (optional, if desired by the company's leadership): In this phase, a presentation is made to all assessment participants to engage them in the follow-up processes of corporate development. This phase takes less than a week, with most time spent on discussions with corporate client(s) concerning critical aspects of the assessment.

Overall, the i-TCA assessment process can be as short as a few hours to a few days once the decision to move forward is taken. Data collection and analysis are largely automated in the online survey and subsequent software processing.

\section{Real-Life Examples of i-TCA Competitiveness Assessments}

The i-TCA tool was beta-tested in the winter of 2013 with over 80 Canadian executives in small, medium, and large enterprises. The completion rate was quite high with 41 complete answers to the iTCA survey questions. On average, it took an executive 17 minutes to use the i-TCA tool. Some of the results were of high interest to the companies involved and highlighted the value of the tool for competitively managing innovation. To illustrate this value, this section provides an overview of the assessments of three example companies from the beta-test.

Figure 3 shows the assessment results from company A, which appears to be dreaming of leadership although it does not exhibit many of the characteristics of a leader in its market segment. It is very small, with less than $\$ 100,000$ in revenues after five years, static employment dynamics, and self-declared negative financial performance. Its targeted markets - the United States and Canada - are very large and exhibit fast growth and high-pace dynamics. Company A is very strong in matters of technology advancement, cost of development, suppliers, and product affordability, functionality, and performance. But, it is lacking in all aspects of marketing and commercial positioning in the market. Moreover, its cultural attributes do not describe a company capable of growing to lead in its market segment, especially when it is so brazenly targeting the whole of North America without seeing any direct competitors there. 


\section{A Firm-Level Innovation Management Framework and Assessment Tool}

\section{Sorin Cohn}

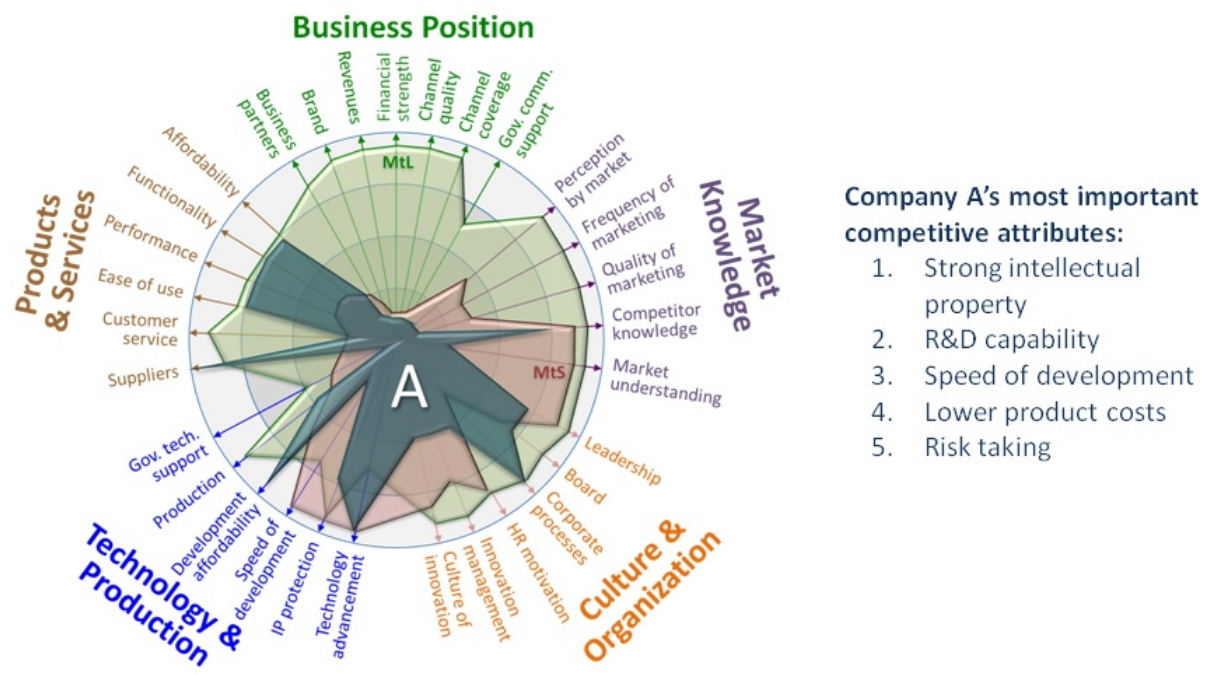

Figure 3. Example A: a company that considers itself "managed to lead"

As described by its i-TCA map, such a company needs a lot of innovation beyond its technology and product if it is serious about market leadership. However, the company may be well positioned for a quick sale if it can prove the value of its IP-protected technology and find a suitable acquirer. Thus, company A sees itself as an MtL company, but in practice, its own i-TCA assessment shows that it is performing more like an MtS company.

In contrast, Figure 4 provides the assessment results from company B, a small ICT software company. The company has revenues below $\$ 100,000$, but it shows some positive financial performance despite it being in existence for less than five years. Its primary markets are USA and Western Europe. These markets are characterized by fast growth and pace of change, but there are few direct competitors, most of which come from the United States. Company B is being managed for a quick sale and appears relatively well positioned to achieve it. As highlighted by its i-TCA map, company B may sell more profitably if it were to apply some innovative actions in matters of marketing, in stronger leadership, and in better protection of intellectual property. Also, it could take advantage of more government support in the technology areas.

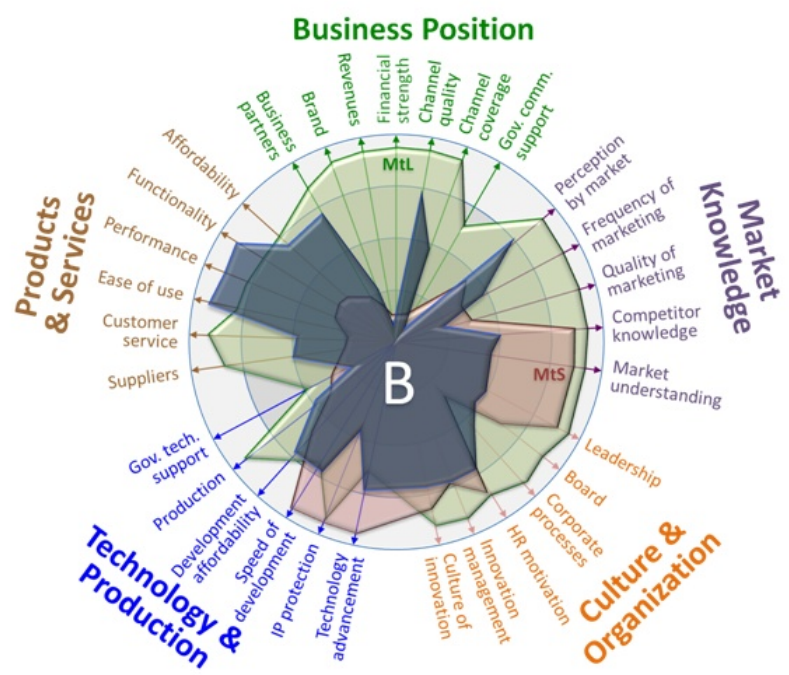

Company B's most important competitive attributes:

1. Strong channels to market

2. Performance and quality of products

3. Speed of development

4. Range of products and services

5. Quality of customer service

Figure 4. Example B: a company that considers itself "managed to sell" 


\section{A Firm-Level Innovation Management Framework and Assessment Tool}

\section{Sorin Cohn}

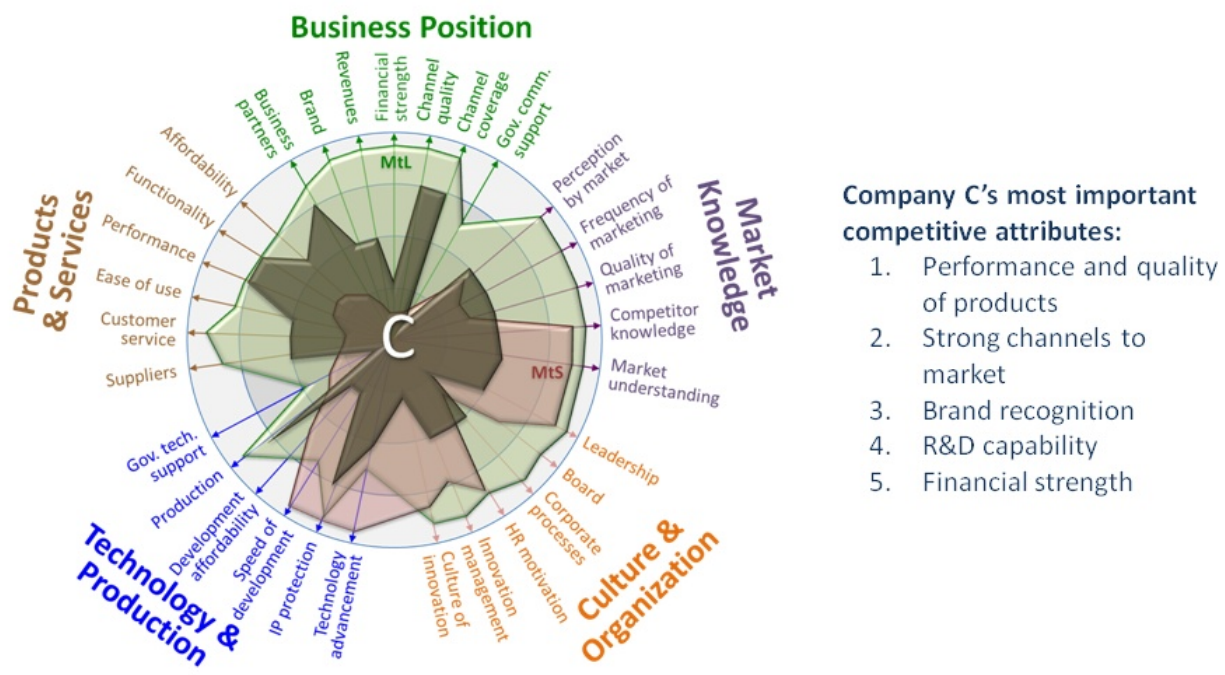

Figure 5. Example C: a large company that considers itself "managed to lead"

Finally, Figure 5 shows the assessment results from company C, which is pursuing a typical "techno-drive" for leadership against global-strength competitors native to the targeted markets of the United States and Western Europe, which are large but with small growth and slow-pace dynamics in the specialized ICT sector of the company. This company is large and mature (i.e., it is over 30 years old and has over 1000 employees), and it has a positive financial performance with annual revenues over $\$ 200$ million.

As determined by its own i-TCA assessment, company $\mathrm{C}$ is far from a leadership position, largely due to its weak board and non-competitive performance concerning development (speed and cost), marketing, customer support, and channels to market - all of which result in poor brand recognition, low revenues, and poor financial strength. It is difficult to think of this company becoming a leader unless it adopts a different innovation strategy and pursues innovations specifically in the areas of evident weakness.

All three of these examples are based on assessments by top-level executives in each company. Still, they are "single-person" assessments and, while instructive, should be followed by full executive-team assessments before undertaking major changes in competitive management and the innovation strategies to be pursued for attaining the corporate goals. Special attention needs to be paid to the company culture because some of the examples above (especially companies A and C) highlight striking levels of misalignment between the company's business goals, its corporate culture, and its innovation strategies.

\section{Conclusion}

Industry needs adequate models for the management of innovation activities - models that are capable of tying the various aspects of the innovation domains: products, services, processes, the organization itself, people, and business strategies. The innovation model must enable meaningful, timely, and easy-to-use measurements of performance and capabilities to optimize the use of resources, to adjust the focus of activities, and to ensure that the competitive objectives are achieved.

The v-CIM framework and the i-TCA tool provide both large and small companies with an effective methodology for devising competitive management strategies based on an assessment of their competitive status and by monitoring their progress towards improved market positions. The methodology is straightforward and the tools are easy to apply. The i-TCA tools provide an at-aglance visual map capable of pinpointing the strengths and weaknesses of a company as perceived by the senior management of the company itself - the people who know best "what is and what is not". Thus, they enable the corporate leadership to act in an informed manner, with judicious innovation strategies and well-targeted activities to bring about tangible results most efficiently. 


\section{A Firm-Level Innovation Management Framework and Assessment Tool} Sorin Cohn

By using the i-TCA tool, companies benefit by being able to:

- clarify their vision and business goals in a realistic, competitive context

- map their position on the evolutionary journey to fulfill their business goals

- engage and mobilize corporate leaders and other key players

- enhance the corporate strengths with a consensus on innovation strategies and further developments in accordance with the company's competitive assessment and its vision of its future

- determine a series of actionable plans, with priorities to mobilize resources

The i-TCA tool is being developed for volume commercialization. It will provide several versions enabling basic as well as in-depth, detailed competitiveness assessments vis-à-vis primary and secondary competitors in targeted markets. The beta version and associated consulting services are available from the author and his company, BD Cohnsulting.

The i-TCA tool also has value for organizations interested in macro views of the entire national industry and its key constituent sectors. A large-scale competitiveness assessment could establish a database for benchmarking industry sectors to discern areas of sectorial weakness and determine remedial actions.

The criteria by which we measure relevance and success have a profound impact on how we examine, manage, and judge innovation. Moving away from "appreciation in the eye of the beholder" to objective methods for measuring innovation enables the transition from innovation management as an art to being a results-oriented engineering practice.

\section{About the Author}

Sorin Cohn has 35 years of international business and technology experience, having been involved in most facets of innovation development: from idea to research and lab prototype, from technology to product, and then to market success on the global stage. He has developed new technologies, created R\&D laboratories, started new product lines, and initiated and managed new business units. Sorin has several essential patents in web services, wireless, and digital signal processing, as well as over 70 publications and presentations. He has also been Adjunct Professor at the University of Ottawa. He is a Killam Scholar, and he holds a PhD in Electrical Engineering, an MSc in Physics, and an MEng in Engineering Physics. Sorin is President of BD Cohnsulting Inc. As well, he acts as Leader of Innovation Metrics at The Conference Board of Canada and as Chief Program Officer of i-CANADA. He is also Member of the Board of Startup Canada as well as the Board of the Centre for Energy Efficiency.

Citation: Cohn, S. 2013. A Firm-Level Innovation Management Framework and Assessment Tool for Increasing Competitiveness. Technology Innovation Management Review. October 2013: 6-15.

Keywords: firm-level innovation, innovation models, management, competitiveness assessment, innovation performance, management effectiveness, tools 